\title{
REGIONAL CONVERGENCE THEORIES - CONFORMITY WITH THE EU DEVELOPMENT
}

\author{
S. Totev* \\ Economic Research Institute, Bulgarian Academy of Sciences, Sofia, Bulgaria
}

\begin{abstract}
A critical review of neoclassical and new economic theories on their correspondence to empirical results for economic development has been made. In the light of these theories, three leading hypotheses for convergence have been considered -- "unconditional $\beta$-convergence", "conditional $\beta$-convergence" and "club convergence". An assessment was made, for the existence of economic convergence in the EU countries at different levels EU-28, EU-15 and the new member states of Central and Eastern Europe, for the period 2007 - 2017 Based on the obtained results, some summaries and conclusions are made.
\end{abstract}

Key words: Economic theories, Regional convergence, EU'

\section{INTRODUCTION}

Achieving convergence under certain conditions is a fundamental vision of the neoclassical economic model (also known as the exogenous growth model -- the Solow's growth model) accepted by many authors as a basic theory of economic development in long run. The main assumptions of this model are based on the neoclassical production function - constant scale of production, decreasing marginal productivity of capital, exogenously determined technical progress and interchangeability of factors of production, labour and capital. The leading requirements for achieving convergence are that the economies of the countries are homogeneous in terms of basic socio-economic characteristics. In this case, according to the neoclassical theories, the initial conditions in the long run are not decisive for economic development and in the presence of homogeneity of the abovementioned characteristics, economic convergence will occurred over time.

\section{REGIONAL CONVERGENCE THEORIES}

Neoclassical theories can hardly give a

\footnotetext{
* Correspondence to: Professor, Dr. Stoyan Anastassov Totev, Economic Research Institute, BAS, 3, Aksakov Street, 1040-Sofia, P.O. Box 788 Bulgaria, Tel: (+3592)8104046, Fax: (+3592)9882108, E-Mail: stotev@yahoo.com
}

complete explanation of the current development of the world economy, incl. and that in the EU. The understanding that a balanced equilibrium economic development can be achieved (even as a theoretical concept) is very restrictive given the diversified influence of a number of factors - an example of this is the global economic crisis that occurred in 2008. .The logical question also arises, what is this balanced development and why comprehensive real examples of its realization cannot be given.

As mentioned, according to these theories, convergence under certain conditions will be achieved in the long run, however maintaining the homogeneity of certain factors for such a period is a requirement that is difficult to accomplish, such as the rate of change of labour force even for the EU [1]. Another factor that can hardly be considered feasible is the assumption of full competitiveness. One of the most serious criticisms of the neoclassical model is the perception of technical progress as an exogenous factor.

The main reason for the emergence of new economic theories is the need to take into account the empirical results, which cannot be confirmed in the light of the neoclassical model. The new economic-geographical 
theory, as well as the new theory of trade, present a different vision of the possible effects due to the integration and specialization of the particular industries in a regional aspect. It is assumed that trade can take place according to the neoclassical theory, but not in all countries. This defines integration processes (at least in the initial stages) as such that lead to greater benefits for industrialized regions and to increasing disparities between rich and poor countries and regions [2]. The new economicgeographical theory advocates the view that the central regions of the EU tend to specialize and export high-tech industrial products to the periphery. The periphery in turn, specializes in the production of products with low technological processing or products - all this leads to an increase of the differences.

The new economic theories include as endogenous many and various factors - of economic, social and demographic nature. This leads to the participation of such indicators, which are sometimes difficult to combine - in simple terms, a study of convergence is provided under conditions that are sometimes incompatible. A major weakness of a number of studies related to new economic theories is that their models are considered adequate by their authors because they reject the validity of the neoclassical model by pointing out its inconsistency with the results of empirical research, which in itself does not mean that the new economic theories are necessarily valid in this cases.

\section{BASIC CONVERGENCE HYPOTHESES}

The convergence hypotheses between countries or regions are subject to different interpretations. The choice according to economic characteristics is generally limited to the search for convergence in terms of growth rates, in terms of income or productivity of productions' factors.

The so-called 'unconditional $\beta$-convergence' is closely linked to the neoclassical theory and implies that weaker economies grow faster than developed ones and because of that income convergence takes place in the long run. The hypothesis of "conditional $\beta$ convergence" is associated with new economic theories and in particular with the new economic-geographical theory [2]. It is assumed that each economy tends to its own balanced development according to the conditions determined by the new economic- geographical theory. In this case, differences between countries and regions may decrease, but may also increase over time. There are many authors who share the understanding that for the EU countries empirical research supports "conditional $\beta$-convergence" rather than "unconditional $\beta$-convergence" [3].

Another leading hypothesis is that of "club convergence" - different regimes of development. It refers to countries (regions) with relatively close conditions (with close economic, social and managerial environment). According to this hypothesis, countries and regions with close socio-economic conditions tend to converge economically with each other. The club convergence theory may not be interpreted necessarily in the light of one or another of the mentioned above economic theories.

Obviously, economists are not united on how the convergence is carried out. There are often radically different views on the manner, object and possibilities for assessing the convergence processes and their theoretical justification even for same object of research. At the same time, the development of economic processes poses new challenges to each already tested model to meet the new changing conditions. Solow himself [ 4 p. 640], emphasizes that in the theory of growth there can be nothing given once and for all, how a convergence take place for each country at any time, once there is a development of technology, demographic and other changes.

The results of empirical research, specifically for the EU, lead most economists to come to the idea of the dualistic nature of the development of the countries of the Union (difference in development between northsouth or centre-periphery), i.e. to the understanding that the processes of convergence and divergence depend on the level of economic development, a development which in the European Economic Area is largely a result of the geopolitical location of the countries $[5,6]$.

The main question that has not yet found an acceptable answer is not so much whether the two processes coexist (convergence and divergence), but to clarify the growth of differences or convergence processes, at what stages of economic development and when and in which periods are realized in the given 
countries. In practice, reality and development always turn out to be more diverse than theoretical statements, economic reality requires each time to look for new hypotheses and patterns that are difficult to summarize for each case. Therefore, the theoretical formulations should be considered important for the understanding of the ongoing regional processes, but not on the basis of them to design the processes of convergence.

\section{CONVERGENCE PROCESSES IN EU COUNTRIES}

Convergence is most often determined in terms of per capita income. The analysis is based on Eurostat information for the last 10 years for GDP per capita was performed for the following groups of countries - EU-28, EU-15 and EU-11 (EU-15 - includes EU member states before 2004, EU-11 - includes Central and Eastern European countries EU members after 2004, these are the former countries with planned economies. Some Balkan countries for which information is available are also included).

The correlation coefficient between GDP per capita and the dynamics of GDP per capita for the last 10 years estimated for the 28 countries is insignificant. The correlation coefficients were calculated according to the Pearson's linear correlation formula. In the study, these coefficients are interpreted not so much as specific magnitudes, but as indicators that provide an approximate estimate of the strength and direction of a given relation. This is a clear indication that, for the EU-28 as a whole, there is no process of convergence or divergence in terms of GDP per capita. Figure 1 and Figure 2 make it possible to visualize the differences in these two indicators.

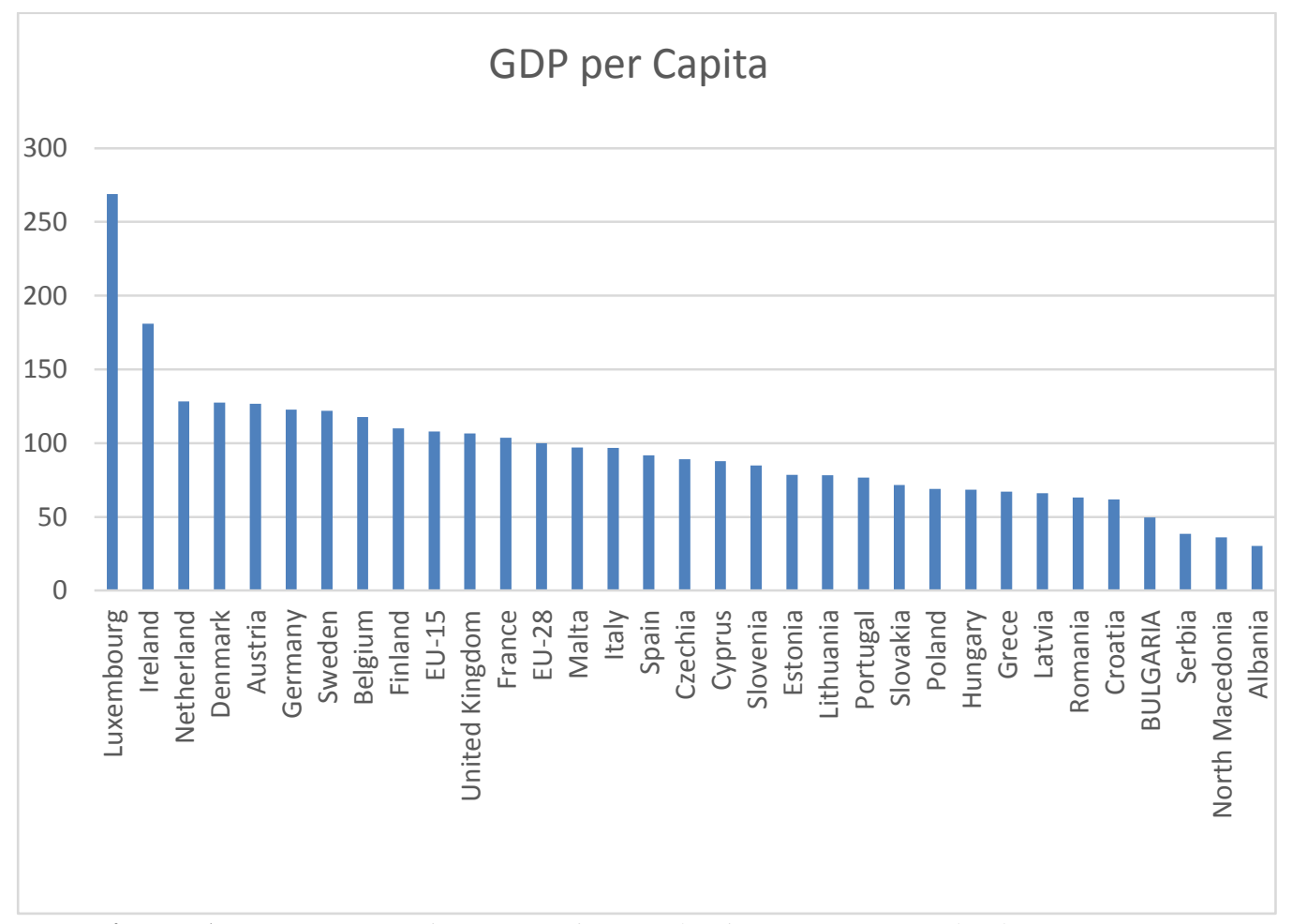

Figure 1. GDP per Capita, 2017 (in Purchasing Power Standard, EU-28=100)

Source: Eurostat

This coefficient however for the EU-15 is positive 0.52 , which means that there is a process of divergence in these countries - in general, those with higher GDP also have a higher growth rate of GDP per capita, see Figute 1 and Figure 2. This process can be defined as visible, but without causing at least at this stage a large increase in differences. This coefficient between the EU-11 countries is negative, but not high 0.39 . This determines low process of convergence between these countries.

If we exclude from the EU-15 countries, the group of Southern European countries with the abbreviation PIGS (Portugal, Italy, Greece and Spain), then the correlation coefficient between the EU-11 countries together with the thus reduced EU-15 countries is minus 0.37. This correlation coefficient indicates that, without 
being clearly expressed, there is a process of convergence between these countries, in other words, the EU-11 countries are reducing their differences with the EU average value. So, the data for GDP per capita and the dynamics of this indicator give grounds to claim that there is a process of convergence for the EU-11 countries. This process is not typical for those of the EU-15, we can rather talk about a process of divergence for them.

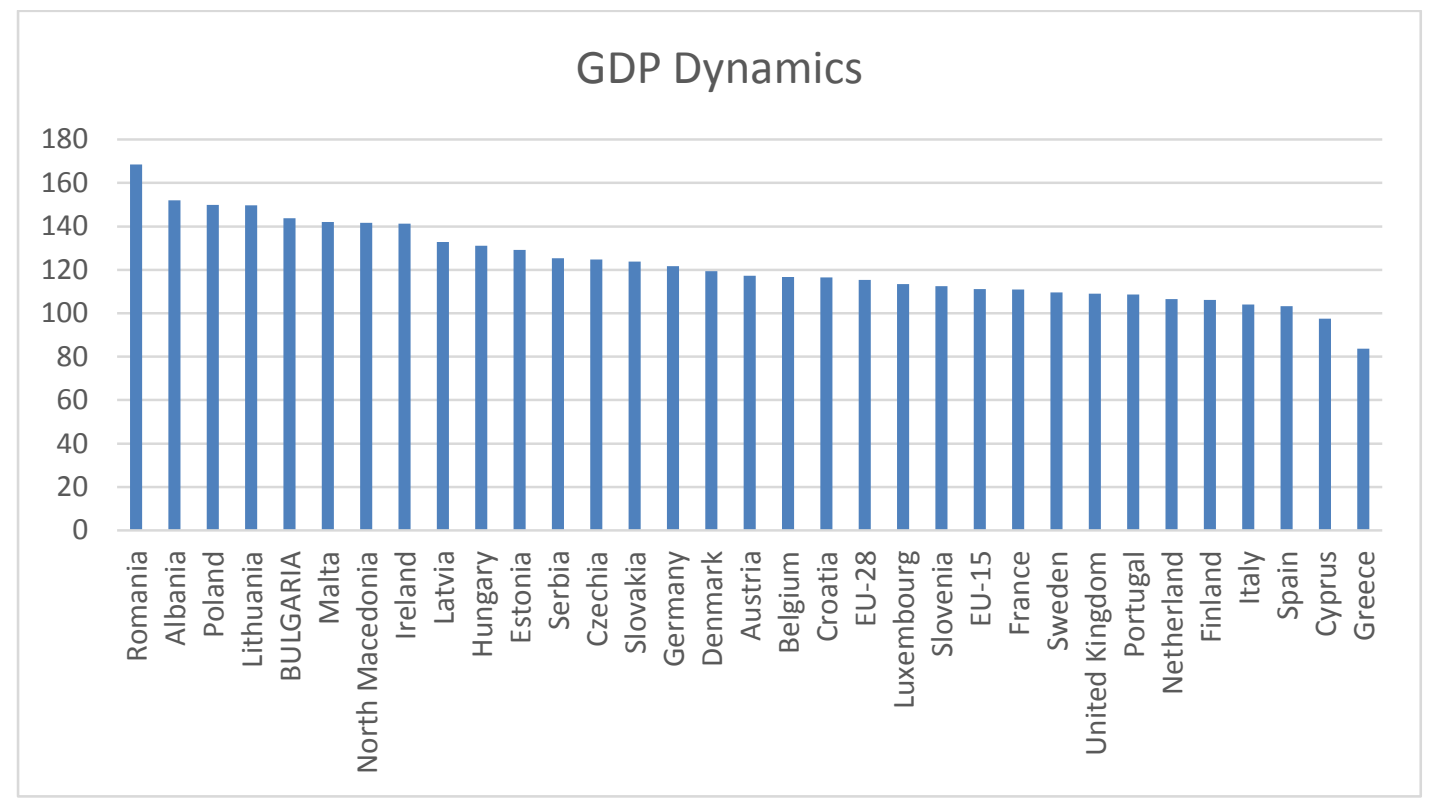

Figure 2. Dynamics of GDP per Capita, 2017/2007 (in Purchasing Power Standard, \%) Source: Eurostat

The fact that there is a certain process of economic divergence between the EU-15 countries, which mainly leads to lagging behind countries such as Greece, Portugal and to some extent that of Cyprus and even Italy. They are characterized by low GDP per capita and low dynamics of this indicator, that can be linked them to their geographical location and to draw a parallel with the weaker economic indicators of the similarly located geographically Balkan countries. Following this logic, it can be assumed that the observed convergence processes of the Balkan countries will be a process that will weaken over time until they approach the economic level of countries such as Greece and Portugal.

The results determining the convergence of the EU-11 countries to the EU-28 averages, are close to the understanding of Paci, Pigliaru [7], for the presence of unconditional $\beta$ convergence, which based on empirical studies determine that such convergence is observed, but it is valid for less developed countries, which implicitly means that it refers to a certain stage of development of these countries.

\section{CONCLUSIONS}

Despite the fact that convergence theories do not fully fit into modern economic development, they are therefore theories, to make assumptions based on them for the sake of the analysis with the clear understanding that these assumptions cannot be fully achieved in practice. This makes them theories and this does not diminish their importance for the analysis. However, to make forecasts based on them is implausible. In this sense, the acceptance of the postulates of one or another theory in the formation of EU regional policy is not appropriate.

In the light of what has been said, as attractive as it may sound, according to some theories, to achieve convergence through overall balanced growth, this is in no way supported by empirical research. Therefore, in order to be able to look for a general positive trend of favourable results of economic integration not only for rich but also for poor countries and regions, the EU needs to have a clear and effective regional policy that does not rely that the economic growth will resolve issues on its own. 


\section{ACKNOWLEDGMENT}

The development of this report was supported by the Ministry of Education and Science in Bulgaria through the National Research Program "Healthy Foods for a Strong Bioeconomy and Quality of Life", approved by DCM № 577 / 17.08.2018.

\section{REFERENCES}

1. Barro, R., Sala-i-Martin, X., Economic Growth, Cambridge. Massachusetts, MIT Press. (second edition) USA, 2003.

2. Fujita, M., Krugman, P., Venables, A., (2001), The spatial economy: cities, regions and international trade. Cambridge. Massachusetts, MIT Press. USA, 2001.

3. Herz B. and Vogel, J., Regional Convergence in Central and Eastern Europe: Evidence from a Decade of Transition. Bayreuth University Economic Discussion, Paper No. 13-03, 2003.
4. Solow, R., Neoclassical Growth Theory. In: Taylor JB, Woodford M (eds) Handbook of Macroeconomics (vol. 1). North Holland, Amsterdam, pp. 637-667. 1999.

5. Petrakos, G., Rodrigues-Pose, A. and Rovolis, A., Growth, Integration and Regional Inequalities in Europe. Environment and Planning A, 37: 18371855, 2005.

6. Totev, S. and Sariiski G., The Spatial Distribution of Labour Intensive Industries in the EU. Regional and Sectoral Economic Studies. Published by the Euro-American Association of Economic Development, vol 8-1. January-June, 2008.

7. Paci, R. and Pigliaru F., Structural change and convergence: an Italian regional perspective. Structural Change and Economic Dynamics, vol. 8, Number 3 p.p. 297-318. Discussion Paper Series, 12(11): 219-242, 1997. 